\title{
Whole conversion of agro-industrial wastes rich in galactose-based carbohydrates into lipid using oleaginous yeast Aureobasidium namibiae
}

\author{
Zhi-Peng Wang ${ }^{1 *}\left(\mathbb{D}\right.$, Xin-Yue Zhang ${ }^{1}$, Yan Ma' ${ }^{1}$ Jing-Run Ye ${ }^{1}$, Jing Jiang ${ }^{2}$, Hai-Ying Wang ${ }^{3}$ and Wei Chen ${ }^{\text {** }}$
}

\begin{abstract}
Background: Raw materials composed of easily assimilated monosaccharides have been employed as carbon source for production of microbial lipids. Nevertheless, agro-industrial wastes rich in galactose-based carbohydrates have not been introduced as feedstocks for oleaginous yeasts.

Results: In this study, Aureobasidium namibiae A12 was found to efficiently accumulate lipid from soy molasses and whey powder containing galactose-based carbohydrates, with lipid productions of $5.30 \mathrm{~g} / \mathrm{L}$ and $5.23 \mathrm{~g} / \mathrm{L}$, respectively. Over $80 \%$ of the fatty acids was $C_{16: 0}, C_{18: 0}, C_{18: 1}$, and $C_{18: 2}$. All kinds of single sugar components in the two byproducts were readily converted into lipids, with yields ranging between $0.116 \mathrm{~g} / \mathrm{g}$ and $0.138 \mathrm{~g} / \mathrm{g}$. Three a-galactosidases and five $\beta$-galactosidases in the strain were cloned and analyzed. Changes of transcriptional levels indicated GalB and GalC were key a-galactosidases, and GalG was key $\beta$-galactosidase. In $10 \mathrm{~L}$ fermentor, lipid production from SM and WP achieved $6.45 \mathrm{~g} / \mathrm{L}$ and $6.13 \mathrm{~g} / \mathrm{L}$, respectively. $\beta$-galactosidase was responsible for lactose hydrolysis; sucrase and a-galactosidase both contributed to the efficient hydrolysis of raffinose and stachyose in a cooperation manner.
\end{abstract}

Conclusions: This is a new way to produce lipids from raw materials containing galactose-based carbohydrates. This finding revealed the significance of sucrase in the direct hydrolysis of galactose-based carbohydrates in raw materials for the first time and facilitated the understanding of the efficient utilization of galactose-based carbohydrates to manufacture lipid or other chemicals in bioprocess.

Keywords: Lipid, Soy molasses, Whey powder, a-Galactosidase, $\beta$-Galactosidase

\section{Background}

Microbial lipid can be produced with high efficiency and has no competition from edible oil. Thus, microbial lipid has become important sources for producing biodiesel and other chemicals now $[15,39]$. Among the lipid-producing microorganisms, oleaginous yeasts are attractive lipid producers for their rapid growth, large biomass, and high lipid yield [19, 33]. The reported oleaginous yeasts mainly belong to several genera, such as Aureobasidium,

*Correspondence: wangzpmbio@163.com; chenwei@qau.edu.cn ${ }^{1}$ School of Marine Science and Engineering, Qingdao Agricultural University, Qingdao 266109, Shandong Province, China

Full list of author information is available at the end of the article
Candida, Cryptococcus, Lipomyces, Rhodotorula, Rhodosporidium, Trichosporon, and Yarrowia [8]. Among them, Aureobasidium pullulans, Lipomyces starkeyi, Yarrowia lipolytica, and Rhodosporidium toruloides can accumulate high level of neutral lipids, over $60 \%$ of their dry cell weight, from different feedstocks $[8,28,31]$.

At present, the high production cost, especially the cost of carbon source for fermentation, impedes the industrial applications of microbial lipids [8]. In view of this, accumulating lipid from low-cost substrates is a feasible strategy to lower the production cost. A variety of raw materials or biowastes, including corncob, corn stover, wheat straw, cassava starch, waste oils, inulin, sugarcane bagasse, and sugarcane molasses, have been employed original author(s) and the source, provide a link to the Creative Commons licence, and indicate if changes were made. The images or other third party material in this article are included in the article's Creative Commons licence, unless indicated otherwise in a credit line to the material. If material is not included in the article's Creative Commons licence and your intended use is not permitted by statutory regulation or exceeds the permitted use, you will need to obtain permission directly from the copyright holder. To view a copy of this licence, visit http://creativecommons.org/licenses/by/4.0/. The Creative Commons Public Domain Dedication waiver (http://creativeco mmons.org/publicdomain/zero/1.0/) applies to the data made available in this article, unless otherwise stated in a credit line to the data. 
as carbon source for the lipid production by oleaginous yeasts [8]. Generally, raw materials can be converted into available monosaccharides using pretreatment methods, including acid hydrolysis, enzymatic hydrolysis, microbiological pretreatment, and detoxification process [8]. Corncob, corn stover, wheat straw, cassava starch, and sugarcane bagasse were converted into hydrolysate containing glucose as main component [8]. Inulin can be hydrolyzed into fructose [34].

Overall, the carbohydrates in these raw materials above mainly rely on glucose or fructose as monosaccharide unit, which can be easily assimilated. However, some agro-industrial by-products contain plenty of galactosebased carbohydrates, such as lactose and raffinose family oligosaccharides (RFOs) [35]. The galactoside bonds in the sugars are difficult to break up, thereby leading to limited applications and lowered commercial value. Due to lacking galactosidase synthesis and intracellular galactose assimilation pathway, most oleaginous yeasts cannot naturally consume galactose and RFO [35]. In addition, construction of galactose metabolic pathways in most yeast was not easy to achieve [18]. The abundant agro-industrial wastes containing galactose-based carbohydrates, such as whey powder (WP) and soy molasses (SM), have not been introduced as carbon source for lipid production $[18,35]$.

$\mathrm{SM}$ is a main by-product of the soy protein extraction from soybean. As soybean is one kind of staple crops providing plant proteins and lipid, SM is produced in large amount. Generally, SM has a high carbohydrate content of above $30 \%(\mathrm{w} / \mathrm{v})$, mainly containing stachyose, raffinose, sucrose, monosaccharides, and other micronutrients $[10,22,26]$. Owing to the existence of $\alpha-(1,6)$ glycosidic bonds in RFO, SM cannot even be efficiently utilized by non-ruminant animals [35]. WP is a by-product in cheese production, and most of the production was concentrated in European and North America, with an annual worldwide production of about 165 million tons [16]. Despite whey containing many fermentable nutrients, such as lactose, proteins, and lipids, it has not efficiently utilized now [3]. In Europe, it was estimated that only $75 \%$ of the whey was recovered and developed as resources. While in the rest of the world, only than $50 \%$ of the whey was recovered [16].

Aureobasidium spp. has recently been evaluated as an excellent lipid producer and reported to efficiently assimilate various monosaccharides [31]. The genus was found to secrete many kinds of hydrolytic enzymes involved in biomass degradation [31]. In our previous study, several galactosidases were detected among extracellular substances of Aureobasidium sp., indicating the ability of assimilating galactose-based carbohydrates [41]. In this study, Aureobasidium namibiae strain A12 derived from mangrove was screened to accumulate high content of lipid directly from WP and SM.

\section{Results}

Evaluation of lipid producers of the yeast strains from SM Apart from raffinose and stachyose, SM contained high level of conventional sugars, such as glucose, fructose, and sucrose, accounting for more than $40 \%$ of total carbohydrates [35]. These conventional sugars provided enough carbon sources for lipid accumulation of $L$. starkeyi and $R$. toruloides, with the lipid production of $1.80 \mathrm{~g} / \mathrm{L}$ and $1.93 \mathrm{~g} / \mathrm{L}$, respectively (Fig. 1a). The highest lipid content $(47.3 \%, \mathrm{w} / \mathrm{w})$ was observed in the strain A12 system, with the lipid production of $5.30 \mathrm{~g} / \mathrm{L}$ and the biomass of $11.20 \mathrm{~g} / \mathrm{L}$ (Fig. 1a). Obviously, only the conventional sugars in SM cannot support the largescale lipid synthesis of strain A12. In the final culture of typical oleaginous yeasts, the galactose-based carbohydrates, including stachyose, raffinose, and galactose, in the culture of typical oleaginous yeasts remained the same with the original concentrations in the medium (Fig. 1b). Stachyose and raffinose was totally utilized by strain A12 (Fig. 1b). This indicated that the RFO should be converted into lipid in strain A12. The low content of residual sugar also provided another evidence for this.

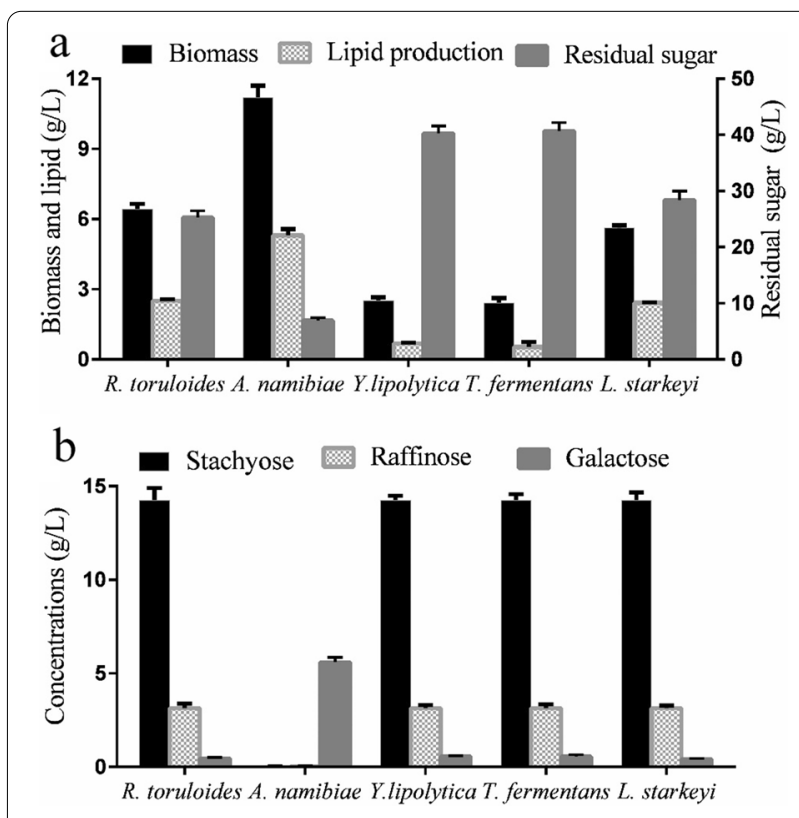

Fig. 1 a Lipid productions of typical oleaginous yeasts and strain A12 from SM. $\mathbf{b}$ Contents of the residual galactose-based carbohydrates in the SM culture of typical oleaginous yeasts and strain A12. Data are given as means \pm standard deviation, $n=3$ 
Evaluation of lipid producers of the yeast strains from WP Many researchers have made efforts to convert WP into citric acid, lactic acid, and lipases [2, 25, 36]. WP also has received a wide attention to serve as the raw material for the production of biofuels recently [18]. A. namibiae strain A12 and other four typical oleaginous yeasts were evaluated from the perspective of the capability to produce lipid from WP, whose main component is lactose. As shown in Fig. 2a, strain A12 possessed the highest lipid content $(48.6 \%, \mathrm{w} / \mathrm{w})$ and was able to accumulate $5.23 \mathrm{~g} / \mathrm{L}$ lipid and $10.72 \mathrm{~g} / \mathrm{L}$ biomass from WP. On the contrary, L. starkeyi, Y. lipolytica, and $R$. toruloides can only accumulate a small amount of biomass and lipid compared with strain A12. As shown in Fig. 2b, four typical oleaginous yeasts can just utilize little amount of the lactose. This indicates that strain A12 can utilize lactose as the main component in WP, while the other three oleaginous strains can only assimilate the monosaccharides with low concentrations as carbon source.

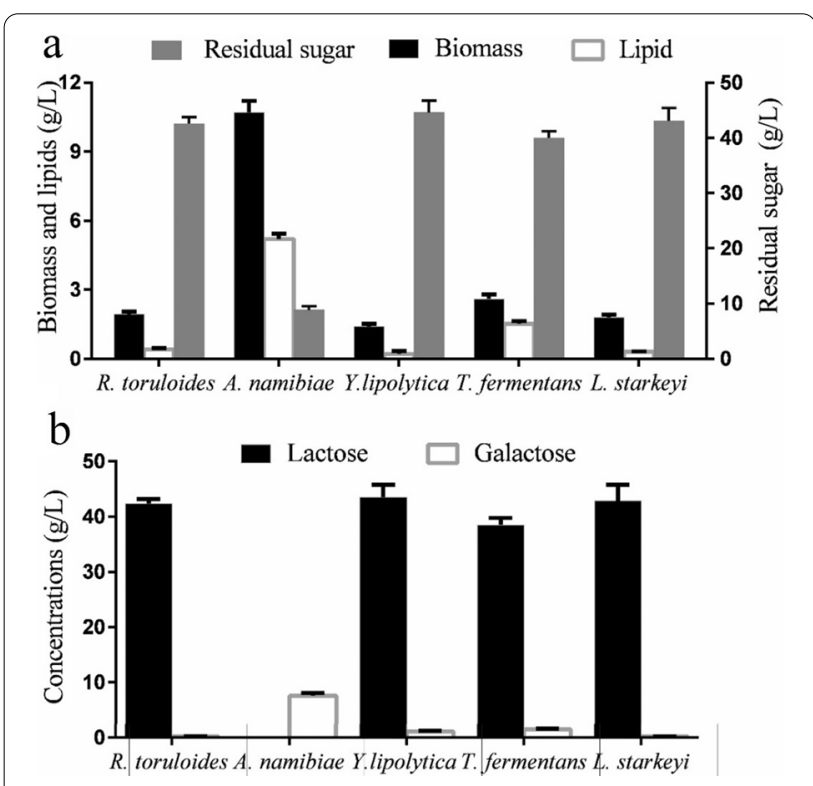

Fig. 2 a Lipid productions of typical oleaginous yeasts and strain A12 from WP. $\mathbf{b}$ Contents of the residual galactose-based carbohydrates in the WP culture of typical oleaginous yeasts and strain A12. Data are given as means \pm standard deviation, $n=3$

\section{Composition of the fatty acids}

Triacylglycerols (TAGs), the reported main components of lipid in oleaginous yeasts, were stored in intracellular lipid droplets: One to three droplets in each cell of strain A12 (data not shown). After being stained by Nile Red, the lipid droplets presented yellow fluorescence which can be observed under a fluorescent microscope with blue excitation light. GC analysis of the fatty acids showed that the content of linoleic acid $\left(\mathrm{C}_{18: 2}\right)$, oleic acid $\left(C_{18: 1}\right)$, stearic acid $\left(C_{18: 0}\right)$, palmitoleic acid $\left(C_{16: 1}\right)$, and palmitic acid $\left(\mathrm{C}_{16: 0}\right)$ in lipid converted from $\mathrm{SM}$ were $9.83 \%, 57.42 \%, 10.51 \%, 2.1 \%$, and $20.14 \%$, respectively (Table 1). Oleic acid $\left(C_{18: 1}\right)$ and palmitic acid $\left(C_{16: 0}\right)$ in lipid of $A$. namibiae converted from SM account for high proportion (78.94\%). The composition of the fatty acids in lipid converted from glucose and WP was rather similar to that converted from SM.

\section{Analysis on the utilization of different sugars}

To further demonstrate the ability of strain A12 to utilize the waste sugars with galactoside bonds, it was cultured in a lipid-producing medium in which a single component in SM and WP was employed as the sole carbon source, including glucose, galactose, fructose, lactose, sucrose, xylose, stachyose, and raffinose. As shown in Fig. 3, the lipid production, biomass, and residual sugars in these fermentations have been compared. The test monosaccharides, which are present in SM and WP or exist as monosaccharide units of other sugars, were all readily converted to lipid. The lipid yield from them was not much different, ranging from $0.116 \mathrm{~g} / \mathrm{g}$ to $0.138 \mathrm{~g} / \mathrm{g}$. This suggests that an efficient galactose and metabolism pathway indeed exists in the strain A12. It should be noted that this strain can even convert xylose into lipid, which is quite challenging for many other yeasts [8]. Besides, it can utilize the sucrose, commonly used as a conventional carbon source, and galactose-based sugars in an efficient manner, revealing the existence of a developed galactosidase system [6, 30].

\section{Galactosidase system in strain A12}

$\alpha$-Galactosidase is effective in catalyzing the generation of $\alpha$-linked galactose residues from various substrates, thus being crucial for the conversion of RFO into conventional

Table 1 Composition of the fatty acids cultivated in different carbon sources

\begin{tabular}{llllrr}
\hline $\begin{array}{l}\text { Fatty acid composition } \\
\text { (\%) }\end{array}$ & $\mathbf{C}_{16: 0}$ & $\boldsymbol{C}_{16: 1}$ & $\mathbf{C}_{\mathbf{1 8 : 0}}$ & $\boldsymbol{C}_{\mathbf{1 8 : 1}}$ & $\boldsymbol{C}_{\mathbf{1 8 : 2}}$ \\
\hline Glucose & & & & \\
SM & $20.56 \pm$ & $3.10 \pm 0.35$ & $10.43 \pm 0.16$ & $58.38 \pm 0.43$ & $7.53 \pm 0.27$ \\
WP & $20.14 \pm 0.43$ & $2.10 \pm 0.12$ & $10.51 \pm 0.61$ & $57.42 \pm 0.89$ & $9.83 \pm 0.42$ \\
\hline
\end{tabular}




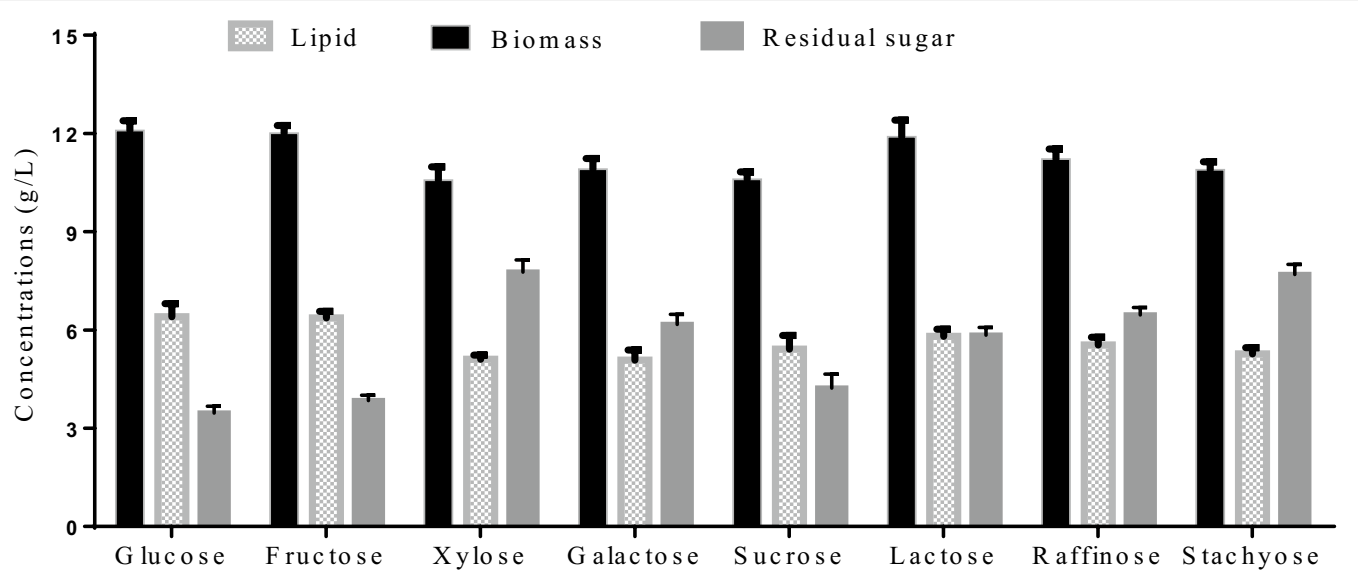

Fig. 3 Lipid productions of strain A12 from single sugar components in SM and WP. Data are given as means \pm standard deviation, $n=3$

carbon source sucrose, while $\beta$-galactosidase is able to cut the $\beta$-linked galactose residue of lactose to yield glucose $[18,35]$. Based on the genome sequence of the type strain for this species, A. namibiae CBS 147.97, the potential galactosidase coding gene in strain A12 was cloned and analyzed. As listed in Table 2, diverse $\alpha$-galactosidases and $\beta$-galactosidases were constituted by different numbers of amino acids. Through analysis, three potential $\alpha$-galactosidases (namely GalA, GalB, and $\mathrm{GalC}$ ) and five potential $\beta$-galactosidases (i.e., GalD, GalE, GalF, GalG, and $\mathrm{GalH}$ ) were found. $\alpha$-Galactosidases in strain A12 have been classified into two glycoside hydrolase families GH27 and GH36. GH27 and GH36 are perceived to have a common ancestral gene and hence they share a common catalytic mechanism. The phylogenic tree showed that GalB and GalC from GH27 are clustered into the same branch, while GalA belongs to another branch (Fig. 4). Each $\alpha$-galactosidase of $A$. namibiae A12 is found very close to that of Aspergillus niger. This is in accordance with the recognition that the genus Aureobasidium is close to $A$. niger in terms of evolutionary relationship [21]. Nevertheless, $\beta$-galactosidases of $A$. namibiae A12 from two glycoside hydrolase families are much more diverse. Although the five $\beta$-galactosidases in A. namibiae $\mathrm{A} 12$ are all separated from $\beta$-galactosidases from plants and bacteria, they diverge in four branches close to specific basidiomycetes or ascomycetes, forming subclasses of specialized enzymes.

When A. namibiae A12 was cultivated in the LP medium containing SM, the transcriptional levels of GALB and GALC increased to $326.3 \%$ and $276.1 \%$ of those cultivated in the LP medium containing glucose (Fig. 5). The transcriptional levels of the genes coding $\beta$-galactosidases were not obviously changed (Fig. 5). GALA cannot be detected by qRT-PCR. When A. namibiae A12 was cultivated in the LP medium containing WP, the transcriptional levels of GALG increased to $456.3 \%$. The results above indicated that GalB and GalC were key $\alpha$-galactosidases for utilizing galactose-based carbohydrates in SM; GalG was key $\beta$-galactosidase for utilizing galactose-based carbohydrates in WP. To explore the characteristics of key galactosidases, GalB, GalC, and GalG were heterologously expressed. The molecular weights of GalB, GalC,

Table 2 Potential a-galactosidases, $\beta$-galactosidases in strain A12 and the basic characteristics

\begin{tabular}{|c|c|c|c|c|c|}
\hline Proteins & Accession & Function & Super family & Amino acids & Signal peptide \\
\hline GalA & MW302897 & a-galactosidase & GH36 & 750 & Yes \\
\hline GalB & MW302898 & a-galactosidase & $\mathrm{GH} 27$ & 452 & Yes \\
\hline GalC & MW302899 & a-galactosidase & $\mathrm{GH} 27$ & 522 & No \\
\hline GalD & MW298673 & $\beta$-galactosidase & $\mathrm{GH} 2$ & 858 & No \\
\hline GalE & MW298674 & $\beta$-galactosidase & GH35 & 1001 & Yes \\
\hline GalF & MW298675 & $\beta$-galactosidase & $\mathrm{GH} 35$ & 1002 & Yes \\
\hline GalG & MW298676 & $\beta$-galactosidase & GH35 & 1009 & Yes \\
\hline GalH & MW298673 & $\beta$-galactosidase & $\mathrm{GH} 7$ & 1071 & No \\
\hline
\end{tabular}



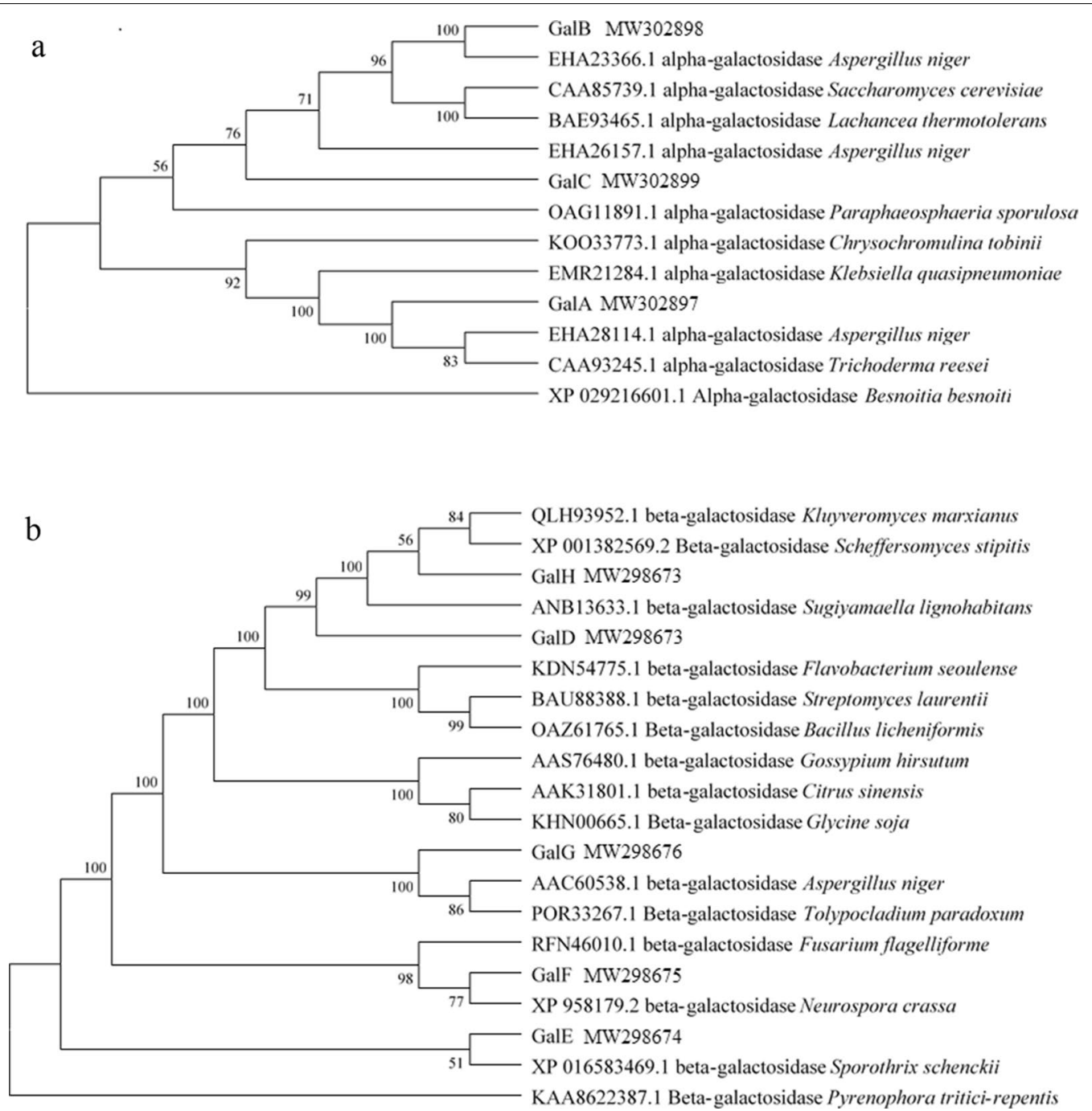

Fig. 4 The phylogenetic tree generated with the neighbor-joining method based on a-galactosidase (a) and $\beta$-galactosidase sequences (b). Branch-related numbers are bootstrap values (confidence limits)

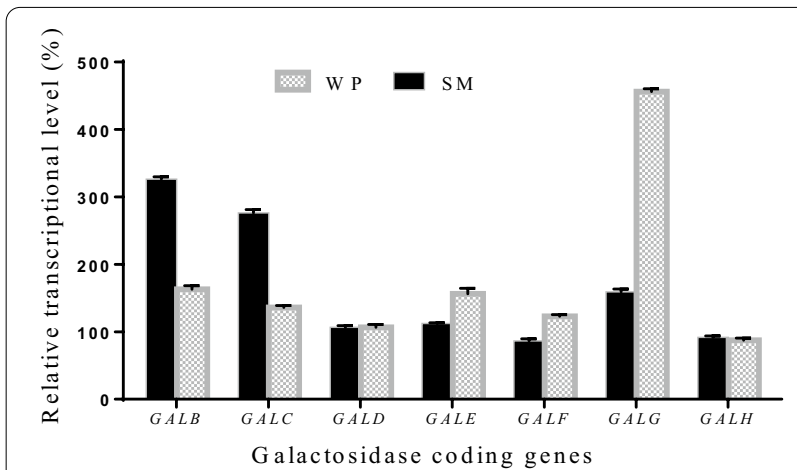

Fig. 5 Changes of transcriptional levels of galactosidase coding genes and GalG were determined as $50.0 \mathrm{kDa}, 55.3 \mathrm{kDa}$, and $107.2 \mathrm{kDa}$, respectively (Additional file 1: Fig. S1-S3). The molecular weights were consistent with those deduced from the amino acid sequences. Recombinant GalB and GalC can efficiently hydrolyze stachyose and raffinose (Additional file 1: Fig. S1, Fig. S2). Recombinant GalB peaked at $40{ }^{\circ} \mathrm{C}$ and was maintained higher than $60 \%$ at $30{ }^{\circ} \mathrm{C}-60{ }^{\circ} \mathrm{C}$; GalB showed high activity and stability in a broad $\mathrm{pH}$ range (4.0-7.0) (Fig.S1). The characteristics of GalC were similar with those of GalB (Additional file 1: Fig. S1, S2). GalG showed higher in lower $\mathrm{pH}$; the optimal $\mathrm{pH}$ for activity and stability was $\mathrm{pH} 4.0$ (Additional file 1: Fig. S3). The three galactosidases can catalyze efficiently in the condition of lipid fermentation. 


\section{Coordination of glycoside hydrolases during the lipid production}

The hydrolysis of carbohydrates in the medium can be realized by inducing microorganisms to generate corresponding glycoside hydrolases. To elucidate the role of glycoside hydrolases in the medium containing SM or WP as the carbon source, their activities and the concentrations of different sugars were monitored at a 12 -h interval in a $10 \mathrm{~L}$ fermentor. The different activities of these glycoside hydrolases can be attributed to the different concentrations of the corresponding enzyme inducers, the substrates of the enzymes in the medium. As shown in Fig. 6a, $\beta$-galactosidase activity was $7.6 \mathrm{U} / \mathrm{mL}$ at $24 \mathrm{~h}$ in WP medium, while the activities of $\alpha$-galactosidase and sucrase were at low levels of $0.6 \mathrm{U} / \mathrm{mL}$ and $1.3 \mathrm{U} / \mathrm{mL}$, respectively. Galactose and glucose derived from lactose hydrolysis were then directed to lipid and biomass synthesis. After $72 \mathrm{~h}$, no lactose was detected and the $\beta$-galactosidase started to decrease. At 96 h, galactose was completely consumed, with a maximal lipid production of $6.13 \mathrm{~g} / \mathrm{L}$. Adequate $\beta$-galactosidase enables the utilization of lactose in WP medium.

$\alpha$-Galactosidase is responsible for converting raffinose family oligosaccharides into conventional sucrose and galactose. As shown in Fig. $6 \mathrm{~b}$ and c, $\alpha$-galactosidases and sucrase were induced much more than those in WP, with $22.6 \mathrm{~g} / \mathrm{L}$ RFO detected. At $24 \mathrm{~h}$, the activity of $\alpha$-galactosidase reached $6.52 \mathrm{U} / \mathrm{mL}$, with reduced content of stachyose and increased galactose; the activity of sucrase reached $4.60 \mathrm{U} / \mathrm{mL}$. However, the content of raffinose just decreased slightly to $3.51 \mathrm{~g} / \mathrm{L}$ at $36 \mathrm{~h}$, as a result of the supplement through the release of raffinose from stachyose cut by $\alpha$-galactosidase (Fig. $6 \mathrm{~b}$, c). Besides, the content of sucrose even increased to the level before $24 \mathrm{~h}$. This indicated that the hydrolysis of
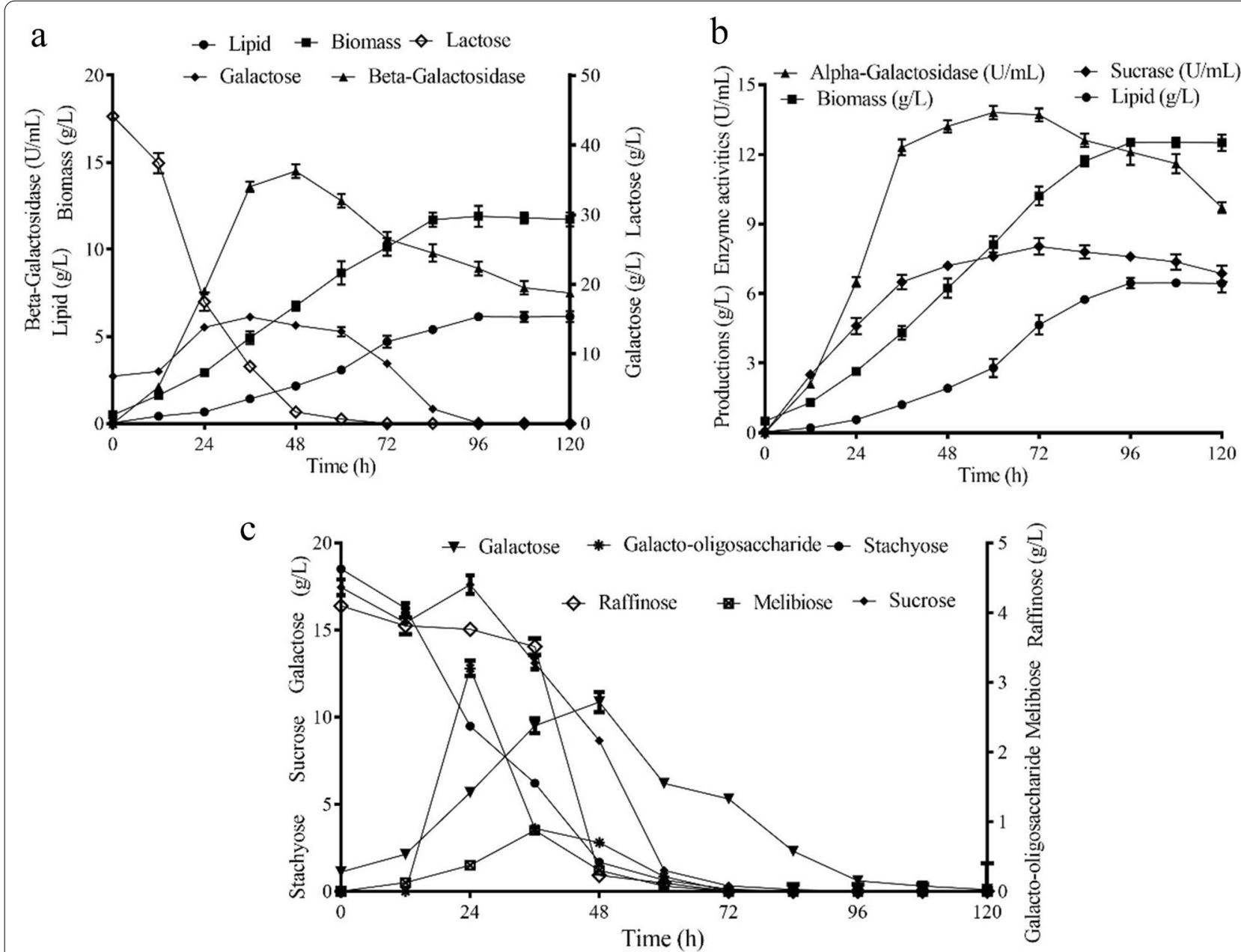

Fig. 6 a Time course of lipid, biomass, galactosidases, and sugar contents in the 10L bioreactor during fermentation by strain A12 from WP. b Time course of lipid, biomass, sucrase and a-galactosidase in the $10 \mathrm{~L}$ bioreactor during fermentation by strain A12 from SM. cTime course of sugar contents during fermentation by strain A12 from SM. Data are given as means \pm standard deviation, $n=3$ 
sucrose by sucrase was slower than its generation from stachyose and raffinose catalyzed by $\alpha$-galactosidase. At $48 \mathrm{~h}$, the activity of $\alpha$-galactosidase and sucrase reached $13.2 \mathrm{U} / \mathrm{mL}$ and $7.2 \mathrm{U} / \mathrm{mL}$, respectively. Under the reaction of $\alpha$-galactosidase and sucrase, sucrose and RFO were both not detected after $96 \mathrm{~h}$, and the lipid achieved a maximal yield of $6.45 \mathrm{~g} / \mathrm{L}$ (Fig. 6b, c).

\section{Discussion}

As far as we know, this is the first time for the introduction of SM as low-cost carbon source in lipid production $[8,10,22,26]$. Benefiting from the low cost and easy availability, SM has become a promising feedstock in China [35]. Moreover, the high carbohydrate content makes SM attractive among researchers and biorefinery industrialists $[8,10,22,26]$. However, the current SMderived fermentations suffer from limited efficiency, as most of them still focused on the utilization of the conventional constituents $[7,10,27,37]$. Up to now, only the synthesis of poly-hydroxyalkanoate, propionic acid, and polymalic acid from RFO in SM was achieved [7, 12, 37].

The tested typical oleaginous yeasts in this study all have been proved capable of accumulating high level of lipid from various carbohydrates with glucose or fructose as the monosaccharide unit. $R$. toruloides accumulates lipid from cassava starch [20]. Inulin, sucrose, and tuber meal of Jerusalem artichoke have been used for lipid production in Aureobasidium pullulans [31]. The lipid content and lipid production of $Y$. lipolytica Polg grown in sugarcane bagasse hydrolysate were $58.5 \%$ and $6.68 \mathrm{~g} / \mathrm{L}$, respectively [32]. Moreover, $R$. toruloides, L. starkeyi, and $Y$. lipolytica can produce lipid with the hydrolysate derived from the pretreatment of wheat straw [38]. As for galactose-based carbohydrates, only $A$. namibiae among the oleaginous yeasts can convert them into lipid. The composition of the fatty acids in lipid produced by $A$. namibiae was similar to that of plant oils [8]. $\mathrm{C}_{18: 1}$ was also the predominant fatty acid in lipid of $R$. toruloides, $L$. starkeyi, and $Y$. lipolytica, with a content of more than $40 \%[8,28,31]$. As revealed in previous studies, the long-chain fatty acids constituted by 16 and 18 carbon atoms were ideal candidates for biodiesel production via methylation.

Generally, very few yeasts possess galactosidases and galactose metabolism pathway, thus resulting in the impossibility to utilize lactose by most yeasts [9]. Actually, A. namibiae was the first oleaginous microorganism reported to produce lipid using SM as the feedstock. In previous studies, only two oleaginous yeasts have been reported able to accumulate lipid from WP with a content of more than $40 \%[6,30]$. Cystobasidium oligophagum has been characterized to efficiently convert WP into lipid. The biomass and the lipid content were $43.1 \%$ and $6.38 \mathrm{~g} / \mathrm{L}$, respectively [30]. In another study, the biomass and lipid production of Cryptococcus curvatus from WP achieved $10.77 \mathrm{~g} / \mathrm{L}$ and $63.4 \%$, respectively [6]. Moreover, a secreted $\beta$-galactosidase was introduced in Y. lipolytica, along with the enhanced cellular galactose metabolism. The engineered strain could achieve the rapid conversion of acid whey, producing $6.61 \mathrm{~g} / \mathrm{L}$ of fatty acids [18]. In $10 \mathrm{~L}$ fermentor, lipid production by $A$. namibiae in the medium containing SM or WP as the carbon source achieved $6.45 \mathrm{~g} / \mathrm{L}$ and $6.13 \mathrm{~g} / \mathrm{L}$, respectively, with lipid content of $53.3 \%$ and $51.5 \%$, respectively (Fig.6a, b). As shown in Fig. 6a and b, lipid production increased slowly than biomass accumulation in the first $48 \mathrm{~h}$, but lipid production increased significantly in the 48-72 h. This indicated the lipid yield enhanced after 48-h culture. Due to the slow growth of the yeast cell, more carbon source was partitioned into lipid synthesis. The similar trend was also be confirmed in the lipid production of $R$. toruloides [20, 34].

The lipid productivity of $A$. namibiae A12 was slightly lower than that of $C$. curvatus strain, and much higher than that of $C$. oligophagum strain, using WP as the carbon source (Table 3). However, the lipid productivity of engineered $Y$. lipolytica strain achieved $0.092 \mathrm{~g} / \mathrm{L} / \mathrm{h}$, remarkably higher than those of other strains. Lipid synthesis flux was significantly enhanced by overexpressing acetyl-CoA carboxylase and diacylglycerol acyltransferase in the engineered strains, thus caused a shorter fermentation period and higher lipid production [3]. The engineering strategy in Y. lipolytica can be adopted in A. namibiae A12 to optimize lipid production. And fed-batch fermentation will be another method to enhance the lipid production.

Generally, similar compositions were found in the composition of fatty acids in the majority of oleaginous yeasts, including Y. lipolytica, L. starkeyi, and strain A12 $[8,28]$. These results confirmed that SM and WP would be the ideal substrates for lipid production. Although the fermentations in SM and WP were probably slowed down due to the hydrolysis of raffinose and stachyose,

Table 3 Comparison of lipid productions by different strains from galactose-based carbohydrates

\begin{tabular}{|c|c|c|c|c|}
\hline Strains & Feedstocks & $\begin{array}{l}\text { Lipid content } \\
(\%)\end{array}$ & $\begin{array}{l}\text { Productivity } \\
\text { (g/L/h) }\end{array}$ & Ref. \\
\hline $\begin{array}{l}\text { C. oligoph- } \\
\text { agum }\end{array}$ & Whey & 44.12 & 0.034 & [30] \\
\hline C. curvatus & Whey & 63 & 0.071 & {$[6]$} \\
\hline Y. lipolytica & Whey & about 45.5 & 0.092 & [18] \\
\hline A. namibiae & $\mathrm{SM}$ & 53.3 & 0.067 & This study \\
\hline A. namibiae & WP & 51.5 & 0.064 & This study \\
\hline
\end{tabular}


lower osmotic pressures were allowed and the biomass was increased. Thus, as largely untapped resources currently, SM and WP deserve arousing attention from A. namibiae system to be a self-sufficient nutrient for numerous potential bioprocesses [8]. This galactosidases system provides molecular basis for strain A12 to utilize sugars with galactoside bonds. Based on the excellent the characteristics of GalB, GalC, and GalG (Additional file 1: Fig. S1; Fig. S2; Fig. S3), the three key galactosidases in Aureobasidium can be a valuable untapped industrial enzyme resource [21]. Besides, the sucrose-utilizing capacity has been proved among Aureobasidium strains to accumulate biopolymer and other products $[1,13$, 24, 37]. In the genome of Aureobasidium namibiae CBS 147.97, ten potential sucrase coding genes have been identified, giving support for the capacity of $A$. namibiae A12 to utilize sucrose in SM.

Unexpectedly, two kinds of sugars not present in SM medium have been detected during the fermentation, which were identified as melibiose and galacto-oligosaccharide. Their existence revealed the neglected fact that the sucrase also functions in the hydrolysis of stachyose and raffinose apart from $\alpha$-galactosidase [29]. Sucrase has been proved to catalyze the release of fructose residues from different substrates, including stachyose and raffinose. Thus, sucrase and $\alpha$-galactosidase both contribute to efficient hydrolysis of RFO in a cooperation manner, rather than in a sequential way $[8,29]$. The sequence of cutting the two kinds of glycosidic bonds influences the generation of intermediate sugars, as shown in Fig. 7. In the case of sole $\alpha$-galactosidase, RFO was converted into sucrose with the release of galactose; when only sucrose exists, melibiose and galacto-oligosaccharide were generated with the release of fructose (Fig. 7). This finding revealed the significance of sucrase in the direct hydrolysis of RFO in raw materials for the first time and facilitated the understanding of the efficient utilization of RFO to manufacture lipid or other chemicals in bioprocess $[8$, 35].

\section{Conclusions}

A. namibiae A12 efficiently accumulate lipid from galactose-based SM and WP. $\beta$-Galactosidase was responsible for lactose hydrolysis in WP; sucrase and $\alpha$-galactosidase both contributed to the efficient hydrolysis of RFO in a cooperation manner. These results demonstrate the feasibility of using SM and WP as a previously untapped resource for biotechnology. This platform strain can be further improved to produce high-value lipid-derived chemicals from waste sugars with galactoside bonds.

\section{Methods}

\section{Strains and media}

Four typical oleaginous yeast strains, i.e., $R$. toruloides R2, Trichosporon fermentans T1, Y. lipolytica URA, and L. starkeyi AM, were preserved at $-80{ }^{\circ} \mathrm{C}$ in our laboratory. Strain A12 was isolated from a plant in Zhanjiang Mangrove National Nature Reserve, and identified as $A$. namibiae. Yeast strains were cultivated in YPD medium (containing $20.0 \mathrm{~g} / \mathrm{L}$ glucose, $20.0 \mathrm{~g} / \mathrm{L}$ peptone, and $10.0 \mathrm{~g} / \mathrm{L}$ yeast extract) [17]. The composition of lipid production (LP) medium included $50 \mathrm{~g} / \mathrm{L}$ glucose, $3.0 \mathrm{~g} / \mathrm{L}$ $\mathrm{K}_{2} \mathrm{HPO}_{4}, 2.0 \mathrm{~g} / \mathrm{L} \mathrm{KH}_{2} \mathrm{PO}_{4}, 0.1 \mathrm{~g} / \mathrm{L} \mathrm{MgSO}_{4} \cdot 7 \mathrm{H}_{2} \mathrm{O}$, and $2 \mathrm{~g} / \mathrm{L}$ corn steep liquor (CSL), with $\mathrm{pH}$ 6.0. When other pure carbohydrates were selected as the carbon source, the concentrations of the carbohydrates remained $50 \mathrm{~g} / \mathrm{L}$. GPPB medium was used for SIase production and contained $30.0 \mathrm{~g} / \mathrm{L}$ glucose, $1.0 \mathrm{~g} / \mathrm{L}(\mathrm{NH} 4)_{2} \mathrm{SO}_{4}, 6.0 \mathrm{~g} / \mathrm{L}$ yeast

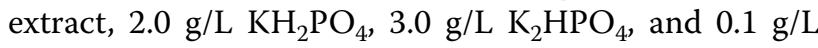
$\mathrm{MgSO}_{4} \cdot 7 \mathrm{H}_{2} \mathrm{O}$ with a $\mathrm{pH}$ of 6.0 [42].

\section{Pretreatment of SM}

SM was adjusted to $\mathrm{pH} 10.0$ with $\mathrm{Ca}(\mathrm{OH})_{2}$ powder which was held for $1 \mathrm{~h}$. Subsequently, the liquid was filtered to remove excess $\mathrm{Ca}(\mathrm{OH})_{2}$ and adjusted to $\mathrm{pH} 6.0$ with $\mathrm{H}_{2} \mathrm{SO}_{4}$, which was kept for $1 \mathrm{~h}$. After 10 min of boiling, the solution was centrifuged at $7000 \times g$, followed by being stored at $4{ }^{\circ} \mathrm{C}$ [41]. The pretreated SM contained $3.32 \%(w / w)$ glucose, $2.81 \%(w / w)$ fructose, $13.42 \%(w / w)$

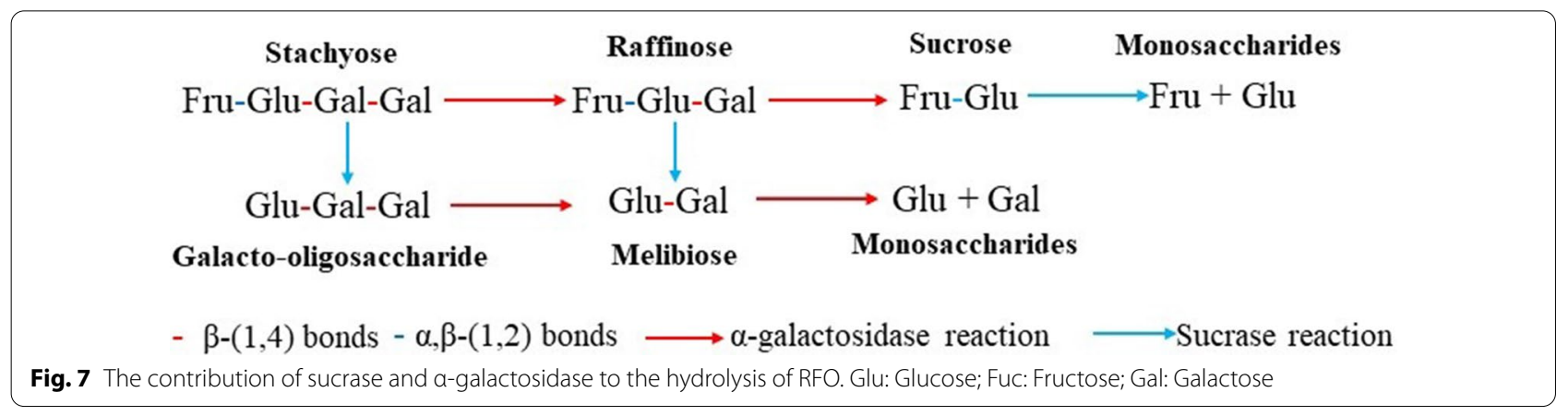


sucrose, $1.73 \%(w / w)$ xylose, $3.15 \%(w / w)$ raffinose, $14.26 \%(w / w)$ stachyose, and $0.78 \%(w / w)$ galactose.

\section{Lipid production at flask level}

Strain A12 was cultivated in $5 \mathrm{~mL}$ YPD medium at $30{ }^{\circ} \mathrm{C}$ for $20 \mathrm{~h}$ which was then switched to $50 \mathrm{~mL} \mathrm{LP}$ medium at the same temperature. The fermentation proceeded for a total of $120 \mathrm{~h}$, after which the broth was centrifuged at $5000 \times g$. The yeast cells were harvested by centrifugation at $5000 \times g$, washed with sterile water, and dried at $80{ }^{\circ} \mathrm{C}$ overnight for the biomass detection. Nile Red $(0.5 \mathrm{mg} / \mathrm{L}$ in DMSO, GenMed Scientifics Inc., USA) was adopted to stain the washed cells $(10 \mu \mathrm{L})$ which were then observed under an Olympus U-LH100HG fluorescent microscope with blue excitation light [31]. In the experiments checking the lipid production from the wastes, glucose in LP medium was absent; SM and low protein WP concentrations were set at $130 \mathrm{~g} / \mathrm{L}$ and $60 \mathrm{~g} / \mathrm{L}$, respectively. So that the sugar content in the medium can be maintained at about $50 \mathrm{~g} / \mathrm{L}$. The initial lactose and galactose in LP medium containing WP were maintained as $44.1 \mathrm{~g} / \mathrm{L}$ and $6.8 \mathrm{~g} / \mathrm{L}$, respectively. The initial LP medium containing SM contained $4.3 \mathrm{~g} / \mathrm{L}$ glucose, $3.7 \mathrm{~g} / \mathrm{L}$ fructose, $17.5 \mathrm{~g} / \mathrm{L}$ sucrose, $2.2 \mathrm{~g} / \mathrm{L}$ xylose, $4.1 \mathrm{~g} / \mathrm{L}$ raffinose, $18.5 \mathrm{~g} / \mathrm{L}$ stachyose, and $1.0 \mathrm{~g} / \mathrm{L}$ galactose, respectively.

\section{Molecular manipulations}

The extraction of genomic DNA from the $A$. namibiae strain was conducted with the TIANamp Yeast DNA Kit (TIANGEN BIOTECH, China). The DNA polymerase was utilized according to the recommendation by the manufacturer (New England BioLabs, USA). The transformation of $E$. coli was realized by the heat shock method of Sambrook et al. [23]. The primers were designed based on the potential gene encoding galactosidase in A. namibiae CBS 147.97, and this potential gene in strain A12 was subjected to PCR amplification. The amplified DNA fragments were then transformed into E. coli $\mathrm{DH} 5 \alpha$ (TaKaRa Biotechnology, China). The $E$. coli transformants were screened on LB agar which contained $100.0 \mu \mathrm{g} / \mathrm{mL}$ ampicillin and play a role in the plasmid amplification and DNA sequencing.

\section{Bioinformatics analysis of galactosidases}

The gene protein sequence was compared using HMMER3 based on the CAZy (Carbohydrate-Active enZYmes) database. In this way, the annotation information of carbohydrate-active enzymes became available [4]. The genes coding for galactosidases and sucrases were amplified using primers listed in Additional file 1: Table S1. E-value < 1e-5 was adopted as the filter condition. SignalP 4.1 server (http://www.cbs.dtu.dk/services/ SignalP-4.1/) was applied to the signal peptide analysis.
The phylogenetic tree was constructed on the basis of reported $\alpha$-galactosidase and $\beta$-galactosidase sequences by virtue of the neighbor-joining method in MEGA version 7.0.

\section{Gene expression level analyses with qRT-PCR assays}

Strain A12 was inoculated for $36 \mathrm{~h}$ at $30{ }^{\circ} \mathrm{C}$ in the LP medium containing glucose, SM, and WP, respectively. Total RNA was isolated using TRIzol reagents described by the manufacturer. RNA concentration was analyzed with NanoDrop2000c spectrophotometer (Thermo Fisher, Germany) and reversed transcribed into cDNA. Real-time PCR was performed in triplicate using a SYBR green assay kit (Toyobo, Japan), with the SYBR realtime PCR master mix (Applied Biosystems). The primers for transcription-quantitative PCR (qRT-PCR) were designed according to the sequences of the genes coding galactosidases; $18 \mathrm{~S}$ rDNA gene was employed as an internal reference (Additional file 1: Table S2). Relative gene expression level changes in LP medium containing SM and WP were analyzed by using the comparative CT method with a $10 \mu \mathrm{L}$ reaction system. Samples from LP medium containing glucose was used as control. All of the amplifications were performed in triplicate from biological triplicates.

\section{Secretory expression of galactosidases}

After codons were optimized, the genes coding galactosidases containing the XPR2 signal peptide gene was synthesized in Synbio Technologies, China. The DNA fragment synthesized in this study was transformed into the $\mathrm{URA}^{-}$strain [42]. After the cultivation in GPPB liquid medium at $30{ }^{\circ} \mathrm{C}$ for $48 \mathrm{~h}$, the positive transformants were detected for their galactosidase activities. The supernatant of positive transformant was adjusted to $\mathrm{pH}$ 7.5 and then loaded on gel filtration chromatography column as well as anion exchange chromatography column (GE Healthcare, USA). The Mw and purity of recombinant galactosidases were verified based on SDS-PAGE on $12 \%(\mathrm{w} / \mathrm{v})$ gel.

\section{Effects of temperature and pH on activity and stability of recombinant galactosidases}

The enzymatic reaction mediated by recombinant galactosidases proceeded in $10 \mathrm{mM}$ glycine- $\mathrm{NaOH}$ buffer (pH 6.0) at temperatures ranging from $10^{\circ} \mathrm{C}$ to $70{ }^{\circ} \mathrm{C}$, the results of which showed the optimal reaction temperature. To investigate the thermal stability of recombinant galactosidases, the enzyme after purification was first incubated at temperatures ranging from $10{ }^{\circ} \mathrm{C}$ to $70{ }^{\circ} \mathrm{C}$ for $12 \mathrm{~h}$ and then the remaining activity at $40{ }^{\circ} \mathrm{C}$ was detected. Tannic acid solutions were prepared with $10 \mathrm{mM}$ buffer at different $\mathrm{pH}$ levels $\left(\mathrm{Na}_{2} \mathrm{HPO}_{4}-\right.$ citric 
acid, $\mathrm{pH}$ 2.0-8.0; glycine- $\mathrm{NaOH}, \mathrm{pH} 8.5-0.0$ ) to act as the substrate for the determination of the optimal reaction $\mathrm{pH} . \mathrm{pH}$ stability was estimated according to the remaining activity after the incubation at $4{ }^{\circ} \mathrm{C}$ for $12 \mathrm{~h}$ in buffer at different $\mathrm{pH}$ levels. All reactions were allowed to proceed in triplicate.

\section{Determination of fatty acid composition of the extracted} oil

The cellular lipids were extracted and weighed with the method of Folch et al. [11]. For the sake of determining fatty acid composition, the oil obtained by Soxhlet extraction was directly subjected to transmethylation and fatty acid esters were then analyzed using gas chromatography (GC) according to the literature procedure.

\section{Enzymatic activity assay and sugar concentration determination}

The $\alpha$-galactosidase activity was evaluated with pNPG as substrate [5]. The reaction was terminated by $\mathrm{Na}_{2} \mathrm{CO}_{3}$ and the solution was filtered through a $0.22 \mu \mathrm{m}$ membrane, followed by high-performance liquid chromatography (HPLC) analysis. The carbohydrate concentration was calculated depending on the retention time and peak area. One unit of the $\alpha$-galactosidase activity (U) was defined as the amount of the enzyme that generated $1 \mu \mathrm{M} p$-nitrophenol per minute at $40{ }^{\circ} \mathrm{C}$ in buffer at $\mathrm{pH}$ 4.5 .

The detection of $\beta$-galactosidase activity was carried out by the similar method [14]. The mixture of the culture $(0.5 \mathrm{~mL})$ and $o$-nitrophenyl- $\beta$-D-galactopyranoside (ONPG, $20.0 \mathrm{mM}, 0.5 \mathrm{~mL}$ ) in $100 \mathrm{mM}$ citrate buffer $(\mathrm{pH} 4.0)$ underwent the incubation at $40{ }^{\circ} \mathrm{C}$ for $10 \mathrm{~min}$. The $\beta$-galactosidase in the mixture was inactivated by $2.0 \mathrm{~mL}$ of $0.5 \mathrm{M} \mathrm{Na}_{2} \mathrm{CO}_{3}$ solution. One unit of the $\beta$-galactosidase activity (U) was defined as the amount of the enzyme producing 1.0 $\mu \mathrm{M}$ ONP per minute in the conditions of this study.

The sucrase activity was detected as reported [40]. The carbohydrate content was determined on an Agilent 1200 system (Agilent Technologies, USA) with amino $\left(\mathrm{NH}_{2}\right)$ column (Thermo Scientific, USA).

\section{Lipid production in $10 \mathrm{~L}$ fermentor}

Large-scale fermentation was performed in Biostat B 10 L fermentors (B. Braun, Germany) for the lipid production from WP and SM, respectively. Strain A12 was first inoculated in YPD medium $(600 \mathrm{~mL})$ as a seed culture and then transferred to the fermentor which contained 6 $\mathrm{L}$ of lipid production medium. In the next step, the fermentation began and lasted for $120 \mathrm{~h}$ under the following conditions: agitation speed: $300 \mathrm{rpm}$, aeration rate: $50 \mathrm{~L} /$ min, temperature: $30{ }^{\circ} \mathrm{C}$, and $\mathrm{pH}$ 6.0. The samples were also taken every $12 \mathrm{~h}$ to determine the biomass, lipid yield, and activities of $\alpha$-galactosidase, $\beta$-galactosidase, and sucrase. Besides, the sugar content was monitored as well.

\section{Supplementary Information}

The online version contains supplementary material available at https://doi. org/10.1186/s13068-021-02031-8.

Additional file 1: Figure S1. (a) SDS-PAGE analysis of recombinant GalB. Lane M, standard Mw markers; lane 1, purified GalB; lane 2, Bovine albumin. (b) Substrate specificity of GalB (c) The pH activity and stability of GalB. (d) Thetemperature activity and stability of GalB. Figure S2. (a) SDS-PAGE analysis of recombinant GalC. Lane M, standard Mw markers; lane 1, purified GalC; lane 2, Bovine albumin. (b) Substrate specificity of GalB (c) The $\mathrm{pH}$ activity and stability of GalC. (d) Thetemperature activity and stability of GalC. Figure S3. (a) SDS-PAGE analysis of recombinant GalG. Lane M, standard Mw markers; lane 1, purified GalG; lane 2, Bovine albumin. (b) The pH activity and stability of GalG. (c) Thetemperature activity and stability of GalG. Table S1. Primers for amplifying genes coding galactosidases. Table S2. Primers used to perform qRT-PCR assays.

\section{Authors' contributions}

ZW conceived the research, performed the fermentation experiments, and wrote the original draft. XZ performed the molecular experiments. YM analyzed the data. JY performed gene sequence analysis. JJ performed purification of the recombinant enzymes. HW supervised the study. WC reviewed and edited the article. All authors read and approved the final manuscript.

Funding

This research was supported by the Natural Science Foundation of Shandong Province (ZR2020MC003), National Natural Science Foundation of China (41806163), National Key R\&D Program of China (2019YFD0901902), "First Class Fishery Discipline" Programme in Shandong Province, a special talent programme, "One Thing One Decision (YishiYiyi)" Programme in Shandong Province, China, and Breeding Plan of Shandong Provincial Qingchuang Research Team (2019).

\section{Declarations}

Ethics approval and consent to participate Not applicable.

Consent for publication

All the authors consent for publications.

\section{Competing interests}

The authors declare that they have no competing interest.

\section{Author details}

${ }^{1}$ School of Marine Science and Engineering, Qingdao Agricultural University, Qingdao 266109, Shandong Province, China. ${ }^{2}$ School of Environmental Science and Engineering, Suzhou University of Science and Technology, Suzhou 215009, Jiangsu Province, China. ${ }^{3}$ Key Laboratory of Sustainable Development of Polar Fishery, Ministry of Agriculture and Rural Affairs, Yellow Sea Fisheries Research Institute, Chinese Academy of Fishery Sciences, Qingdao 266071, China.

Received: 12 April 2021 Accepted: 30 August 2021

Published online: 15 September 2021

\section{References}

1. Al-Araimi SH, Elshafie A, Al-Bahry SN, Al-Wahaibi YM, Al-Bemani AS. Biopolymer production by Aureobasidium mangrovei SARA-138H and 
its potential for oil recovery enhancement. Appl Microbiol Biotechnol. 2021;105(1):105-17.

2. Arslan NP, Aydogan MN, Taskin M. Citric acid production from partly deproteinized whey under non-sterile culture conditions using immobilized cells of lactose-positive and cold-adapted Yarrowia lipolytica B9. J Biotechnol. 2016;231:32-9.

3. Blazeck J, Hill A, Liu L, Knight R, Miller J, Pan A, Otoupal P, Alper HS. Harnessing Yarrowia lipolytica lipogenesis to create a platform for lipid and biofuel production. Nat Commun. 2014;5:3131.

4. Cantarel BL, Coutinho PM, Rancurel C, Bernard T, Lombard V, Henrissat B. The Carbohydrate-Active EnZymes database (CAZy): An expert resource for Glycogenomics. Nucleic Acids Res. 2009;37:D233-8.

5. Cao YN, Yuan TZ, Shi PJ, Luo HY, Ning L, Meng K, Bai YG, Yang PL, Zhou ZG, Zhang ZF. Properties of a novel a-galactosidase from Streptomyces sp. S27 and its potential for soybean processing. Enzyme Microb Technol. 2010;47(7):305-12.

6. Carota E, Crognale S, D'Annibale A, Gallo AM, Stazi SR, Petruccioli M. A sustainable use of Ricotta Cheese Whey for microbial biodiesel production. Sci Total Environ. 2017;584-585:554-60.

7. Cheng C, Zhou Y, Lin M, Wei P, Yang ST. Polymalic acid fermentation by Aureobasidium pullulans for malic acid production from soybean hull and soy molasses: Fermentation kinetics and economic analysis. Biores Technol. 2016;223:166-74

8. Cho HU, Park JM. Biodiesel production by various oleaginous microorganisms from organic wastes. Bioresour Technol. 2018;256:502-8.

9. Domingues L, Guimarães PMR, Oliveira C. Metabolic engineering of Saccharomyces cerevisiae for lactose/whey fermentation. Bioeng Bugs. 2010;1:164-71.

10. Dong J, Du Y, Zhou Y, Yang ST. Butanol production from soybean hull and soy molasses by acetone-butanol-ethanol fermentation. In: Brentin R, editor. SoyBased Chemicals and Materials, ACS Symposium Series 1178, Chapter 2. Washington: American Chemical Society; 2014. p. 25-41.

11. Folch J, Lees M, Slane-Stanley J. A simple method for the isolation and purification of total lipids from animal tissues. J Biol Chem. 1957;226:497-509.

12. Full TD, Jung DO, Madigan MT. Production of poly-beta-hydroxyalkanoates from soy molasses oligosaccharides by new, rapidly growing Bacillus species. Lett Appl Microbiol. 2006;43(4):377-84.

13. Jiang H, Xue SJ, Li YF, Liu GL, Chi ZM, Hu Z, Chi Z. Efficient transformation of sucrose into high pullulan concentrations by Aureobasidium melanogenum TN1-2 isolated from a natural honey. Food Chem. 2018;15(257):29-35.

14. Juers DH, Matthews BW, Huber RE. LacZ $\beta$-galactosidase: structure and function of an enzyme of historical and molecular biological importance. Protein Sci. 2012;221(12):1792-807.

15. Ma Y, Gao Z, Wang Q, Liu Y. Biodiesels from microbial oils: opportunity and challenges. Bioresour Technol. 2018;263:631-41.

16. Macwan SR, Dabhi BK, Parmer SC, Aparnathi KD. Whey and its utilization. Int J Curr Microbiol Appl Sci. 2016;5:134-55.

17. Madzak C. Yarrowia lipolytica: recent achievements in heterologous protein expression and pathway engineering. Appl Microbiol Biotechnol. 2015;99(11):4559-77.

18. Mano J, Liu N, Hammond JH, Currie DH, Stephanopoulos G. Engineering Yarrowia lipolytica for the utilization of acid whey. Metab Eng. 2020;57:43-50.

19. Munch G, Sestric R, Sparling R, Levin DB, Cicek N. Lipid production in the under-characterized oleaginous yeasts, Rhodosporidium babjevae and Rhodosporidium diobovatum, from biodiesel-derived waste glycerol. Bioresour Technol. 2015;185:49-55.

20. Park YK, Nicaud JM, Ledesma-Amaro R. The Engineering Potential of Rhodosporidium toruloides as a Workhorse for Biotechnological Applications. Trends Biotechnol. 2018;36(3):304-17.

21. Prasongsuk S, Lotrakul P, Ali I, Bankeeree W, Punnapayak H. The current status of Aureobasidium pullulans in biotechnology. Folia Microbiol (Praha). 2018;63(2):129-40.

22. Romão BB, da Silva FB, de Resende MM, Cardoso VL. Ethanol production from hydrolyzed soybean molasses. Energy Fuels. 2012;26:2310-6.

23. Sambrook J, Fritsch EF, Maniatis T. Preparation and analysis of eukaryotic genomic DNA. In: Michael RG, editor. Molecular cloning: A laboratory manual. 2nd ed. Beijing: Cold Spring Harbor Laboratory Press; 1989. p. $367-70$.

24. Sheng L, Tong $\mathrm{Q}, \mathrm{Ma} \mathrm{M}$. Why sucrose is the most suitable substrate for pullulan fermentation by Aureobasidium pullulans CGMCC1234? Enzyme Microb Technol. 2016;92:49-55.

25. Silva MDA, Silva TAL, Campos-Takaki GM, Amorim Salgueiro A, Tambourgi EB. Stability of lipases produced by Yarrowia lipolytica in the presence of cheese whey. Chem Eng Trans. 2014;37:703-8.

26. Siqueira PF, Karp SG, Carvalho JC, Sturm W, Rodriguez-Leon JA, Tholozan $J$, Singhania RR, Pandey A, Soccol CR. Production of bio-ethanol from soybean molasses by Saccharomyces cerevisiae at laboratory, pilot and industrial scales. Bioresour Technol. 2008;99:8156-63.

27. Solaiman DK, Ashby RD, Hotchkiss AT Jr, Foglia TA. Biosynthesis of medium-chain-length poly(hydroxyalkanoates) from soy molasses. Biotechnol Lett. 2006;28(3):157-62.

28. Takaku H, Matsuzawa T, Yaoi K, Yamazaki H. Lipid metabolism of the oleaginous yeast Lipomyces starkeyi. Appl Microbiol Biotechnol. 2020;104(14):6141-8.

29. Trindade MI, Abratt VR, Reid SJ. Induction of sucrose utilization genes from Bifidobacterium lactis by sucrose and raffinose. Appl Environ Microbiol. 2003;69(1):24-32.

30. Vyas S, Chhabra M. Assessing oil accumulation in the oleaginous yeast Cystobasidium oligophagum JRC1 using dairy waste cheese whey as a substrate. 3Biotech. 2019;9(5):173.

31. Wang G, Bai T, Miao Z, Ning W, Liang W. Simultaneous production of single cell oil and fumaric acid by a newly isolated yeast Aureobasidium pullulans var. aubasidani DH177. Bioprocess Biosyst Eng. 2018;41(11):1707-16.

32. Wang J, Ledesma-Amaro R, Wei Y, Ji B, Ji XJ. Metabolic engineering for increased lipid accumulation in Yarrowia lipolytica-A Review. Bioresour Technol. 2020;313:123707.

33. Wang ZP, Xu HM, Wang GY, Chi Z, Chi ZM. Disruption of the MIG1 gene enhances lipid biosynthesis in the oleaginous yeast Yarrowia lipolytica ACA-DC 50109. Biochim Biophys Acta. 2013;1831:675-82.

34. Wang ZP, Fu WJ, Xu HM, Chi ZM. Direct conversion of inulin into cell lipid by an inulinase-producing yeast Rhodosporidium toruloides $2 \mathrm{~F} 5$. Bioresour Technol. 2014;161:131-6.

35. Wang ZP, Zhang LL, Liu S, Liu XY, Yu XJ. Whole Conversion of Soybean Molasses into Isomaltulose and Ethanol by Combining Enzymatic Hydrolysis and Successive Selective Fermentations. Biomolecules. 2019;9(8):353.

36. Yalcin SK, Bozdemir MT, Ozbas ZY. Utilization of whey and grape must forcitric acid production by two Yarrowia lipolytica strains. Food Biotechnol. 2009;23:266-83.

37. Yang $H$, Wang Z, Lin M, Yang ST. Propionic acid production from soy molasses by Propionibacterium acidipropionici: Fermentation kinetics and economic analysis. Bioresour Technol. 2018;250:1-9.

38. Yu X, Zheng Y, Dorgan KM, Chen S. Oil production by oleaginous yeasts using the hydrolysate from pretreatment of wheat straw with dilute sulfuric acid. Bioresour Technol. 2011;102(10):6134-40.

39. Zhao Y, Wang HP, Han B, Yu X. Coupling of abiotic stresses and phytohormones for the production of lipids and high-value by-products by microalgae: A review. Bioresour Technol. 2019;274:549-56.

40. Zhang CY, Lin X, Feng B, Liu XE, Bai XW, Xu J, Pi L, Xiao DG. Enhanced leavening properties of baker's yeast by reducing sucrase activity in sweet dough. Appl Microbiol Biotechnol. 2016;100(14):6375-83.

41. Zhang LL, Li J, Wang YL, Liu S, Wang ZP, Yu XJ. Integrated Approaches to Reveal Genes Crucial for Tannin Degradation in Aureobasidium melanogenum T9. Biomolecules. 2019;9(9):439.

42. Zhang P, Wang ZP, Sheng J, Zheng Y, Ji XF, Zhou HX, Liu XY, Chi ZM. High and efficient isomaltulose production using an engineered Yarrowia lipolytica strain. Bioresour Technol. 2018;265:577-80.

\section{Publisher's Note}

Springer Nature remains neutral with regard to jurisdictional claims in published maps and institutional affiliations. 